\title{
Should telecoms liberalisation stop at call termination?
}

\author{
Pietro Crocioni* \\ Case Associates, No. 1 Northumberland Avenue, Trafalgar Square, London, UK
}

\begin{abstract}
In recent years concerns about the degree of competition in the provision of telecommunications call termination services have emerged. While the general consensus is that call origination is becoming more and more competitive, regulatory attention to call termination has widened in scope beyond the incumbent public telephone operators, leading to direct regulation of mobile termination charges in some countries and a debate on whether regulation should also be extended to "non-dominant" networks. This paper assesses whether these concerns are justified, extending the analysis to review the economic literature on reciprocal setting of termination charges between network operators. We conclude that while ex ante regulation of call termination simplifies the work of regulators it does not appear justifiable in all circumstances. (C) 2001 Elsevier Science Ltd. All rights reserved.
\end{abstract}

Keywords: Call termination; Call completion; Interconnection; Mobile; Liberalisation

\section{Introduction}

Access to the incumbent's telecommunications network is crucial for the development of competition. However, the dependency of service provision on access regulation stimulated the search for ways to reduce its importance. The so-called network competition (sometimes called facilities-based competition) appeared to provide the solution. Recent regulatory decisions, however, suggest that, at least for a special type of interconnection known as call termination, regulation will not only be required even under fully-fledged network competition, but it will also extend in scope.

This article examines whether the current regulatory concerns over call termination are justified. Section 2 provides some background information on the access issue and its regulatory framework. Section 3 examines the two main regulatory arguments behind cost regulation of call termination.

\footnotetext{
* Tel.: + 44-20-78725582; fax: + 44-20-3515591.

E-mail address: pietro@casecon.com (P. Crocioni).
} 
First, the claim that call termination is a bottleneck monopoly, giving rise to an "inherent market failure", is reviewed in the light of the UK Competition Commission's (CC) enquiry on fixed-tomobile call charges. Second, a concern often mentioned by the UK Office of Telecommunications (OFTEL), the Australian Competition \& Consumers Commission (ACCC) and the European Commission relates to the potential collusive use of interconnection negotiations. A critical review of the literature on reciprocal network interconnection in Section 4 shows that only under particular circumstances is there an economic justification for extensively regulating call termination.

The article concludes that, although access and interconnection still require regulatory vigilance, consideration of the competitive aspects of the interconnecting telecommunications network operators does not call for ubiquitous regulation of call termination. This is especially true for call termination charges that are set between network operators. These conclusions are particularly relevant in the light of the EU 1999 Communications Review, which will shape the telecommunications regulatory framework in the years to come.

\section{Network access}

In the pre-liberalisation era, state control of the public telephone operators (PTOs) did not require the separation of network from service provision. Liberalisation drastically modified the issue of access to telecommunication networks. Not only the access price had to be made explicit, but also the terms under which service providers could access the PTO's network had to be set. The potential for market foreclosure led most countries to set up regulatory authorities which were entrusted with either the power of setting access charges directly or assumed the role of an arbitrator of last resort should the parties fail to reach mutually satisfactory agreements. ${ }^{1}$ Liberalisation also paved the way to the development of competing and complementary networks which some countries, such as the UK and Australia, actively encouraged. The need to ensure any-to-any connectivity in the new multi-network environment required network operators to negotiate reciprocal access.

Network access can be defined according to the part of the network another operator requires access to. Although the network hierarchy is becoming increasingly complex and varies from country to country it remains useful to schematise it. Subscribers are connected to the local exchange through the local loop. The local loop is the physical circuit between the customer's premises and the telecommunications network's local switch. Trunk network is that part of the network which provides connections between customer-serving local exchanges. The trunk network is ultimately connected to the international network. International network and trunk network services are increasingly competitive and no longer require regulatory intervention. It is the local loop where the competitive constraints on the incumbent PTO are still considered insufficient to relieve it from detail access regulation. An important distinction is between two types

\footnotetext{
${ }^{1}$ The exception is the New Zealand model where there is no industry regulator and the only control is left to the application of competition law. This resulted in Telecom Corporation of New Zealand attempting to delay any interconnection agreement with the new entrant Clear Communications or requiring high access charges. For an account see Mueller (1998).
} 


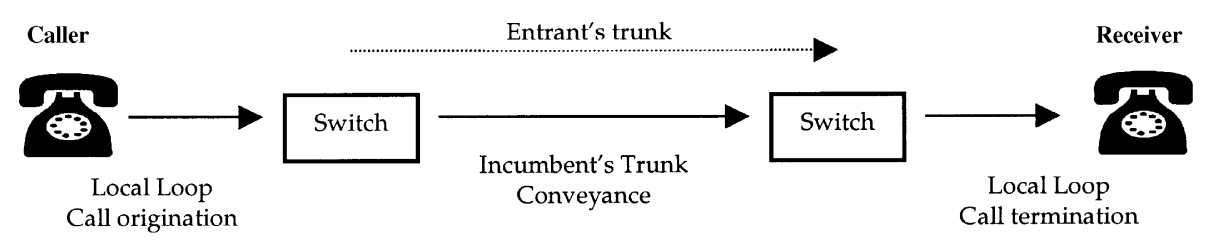

Fig. 1. No local loop network competition.

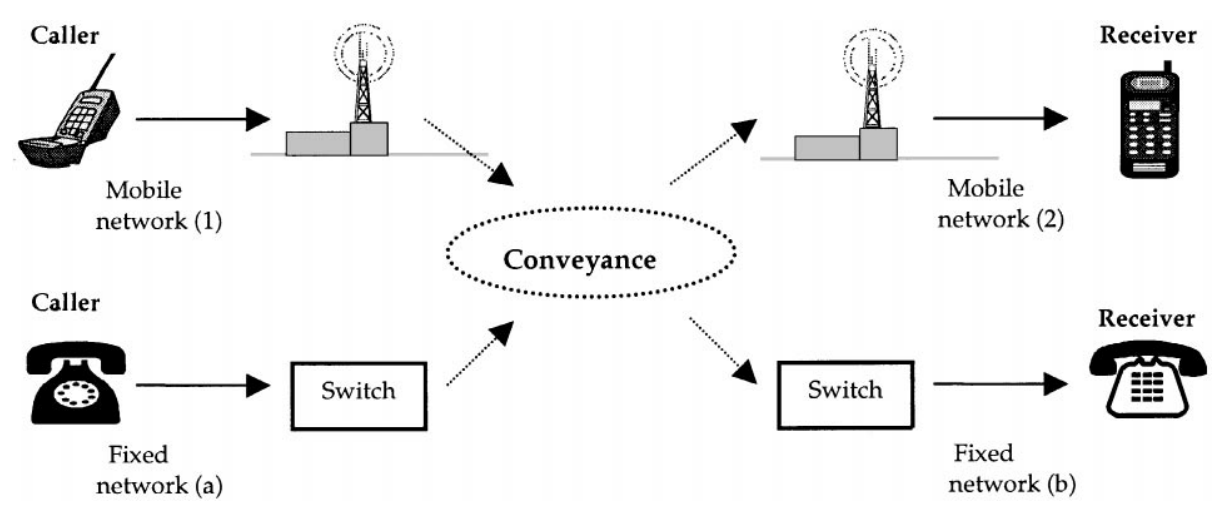

Fig. 2. Local loop network competition.

of access to the local loop depending on whether the call originates or terminates in the local loop network. Call origination refers to the local loop circuit between the caller's premises and the local switch. Conversely, call termination consists of access to the local loop between the local switch and the receiver's premises. The focus of this paper is on access to call termination. A telephone call between two subscribers to the same network is illustrated in Fig. 1. Liberalisation allowed service providers to purchase access to both the origination and termination ends and use a network other than that of the incumbent for long-distance conveyance.

The development of other fixed and mobile networks altered this framework. While service providers still require access to both call origination and termination networks, an increasingly larger proportion of calls now terminates outside the network in which they originated. This means that network operators are often not able to provide a full service unless they purchase call termination services from other networks. These relationships are simply illustrated in Fig. 2 which schematises the interconnection relationships between two mobile and two fixed networks.

\subsection{The evolving structure of telecommunications}

In all EU Member States the structure of the telecommunications industry is rapidly changing and no longer follows the model of a vertically integrated PTO. Deregulation and technological evolution are behind this change. Deregulation "forced" PTOs to supply access to their network in order to allow competition in service provision. Although service competition can gradually reduce the need for extensive retail price regulation, in the absence of structural changes, the need to 
regulate access to the network would remain. The PTOs' monopoly over the provision of access to the local loop had to be reduced if access regulation were to gradually withdraw. The solution envisaged by regulators was to promote network competition. In simple terms, the idea was that once each consumer could choose between two or three local loop network providers the need to regulate access would wane. ${ }^{2}$ Competition in network provision or in access provision was therefore considered to be the key to fostering both retail competition by eliminating the asymmetry between vertically integrated and non-vertically integrated operators and to reduce market power in the network provision side of the industry. However, full facilities-based competition was never deemed either feasible or desirable since it could lead to wasteful duplication of infrastructure. This is the case especially in rural areas where the construction of alternative networks is often not economically justifiable. The incumbent PTOs, therefore, will for a long time be required to make available part of their facilities to third parties.

Regulators have encouraged the roll-out of alternative networks in a variety of ways such as via asymmetric regulation or high access charges. ${ }^{3}$ In the UK OFTEL has actively encouraged the roll-out of cable networks. It has mandated access (or indirect access as called in the UK) to BT's network but not on cable companies because of the potential disincentive effect on cable roll-out investment. ${ }^{4}$ Cable companies were also allowed to supply both telephony and pay TV services allowing them to enjoy economies of scope, while BT was prevented from supplying pay TV services through its network. OFTEL's (1996, para 1.3) goal was to achieve network competition through asymmetric regulation:

OFTEL is optimistic that an increasing proportion of the market for direct connections will be contested by other operators over the next few years. Mercury and other operators are now increasing their number of directly connected customers and cable operators, in particular, will have extended their local networks to cover about $75 \%$ of UK homes within the next five years.

\footnotetext{
${ }^{2}$ For example OFTEL (1998, paras 1.1 and 1.2) described its role in retail price regulation as gradually reducing: “... OFTEL sees a key element of its work as being to stimulate and encourage competition where feasible as a means of moving away from intrusive regulation. There is already a presumption in the current framework against the need to impose the full force of regulatory rules (e.g. detailed price controls) on new telecoms services as they emerge. In the longer run, OFTEL expects that the telecoms industry in the UK will operate like many other private sector industries without the need for detailed regulation (except perhaps in the field of interconnection). (...) OFTEL was primarily created to regulate BT as the incumbent monopoly operator. It is expected that as competition extends across telecoms markets OFTEL's role will change from one of being a company or industry specific regulator and move more towards that of a specialist competition authority for the telecoms industry in the UK".

${ }^{3}$ The network competition model is now under increasing pressures as local loop unbundling (LLU) at long-run incremental cost was recommended by the EU Commission and is gradually adopted by the EU Member States.

${ }^{4}$ OFTEL (1996, para 2.8) pointed at the negative effect of indirect access on the incentives to build new telecommunications infrastructure as the relevant factor in its asymmetric regulation: "A particular concern of OFTEL, therefore, is that companies entering the market investing substantially in infrastructure and providing alternative direct connections to the trunk networks for customers, should not be exposed to cherry picking by indirect access operators. Although there are pricing structures that new entrants could adopt to mitigate this problem, these pricing structures may result in reduced potential consumer welfare of competing infrastructure."
} 
Table 1

Cable network in the EU ${ }^{\mathrm{a}}$

\begin{tabular}{|c|c|c|c|c|}
\hline Country & $\begin{array}{l}\text { Homes } \\
\text { connected } \\
\left(\times 10^{3}\right)\end{array}$ & $\begin{array}{l}\text { Penetration } \\
\text { (homesconn/ } \\
\text { househ) }(\%)\end{array}$ & $\begin{array}{l}\text { Telephony } \\
\text { services }\end{array}$ & Main cable companies \\
\hline Germany & 21,500 & 58 & & $\begin{array}{l}\text { Deutsche Telekom, Tele Columbus, } \\
\text { Kabel-Service Berlin }\end{array}$ \\
\hline Spain & 390 & 3 & $\begin{array}{l}\text { Launch planned } \\
\text { during } 1999\end{array}$ & $\begin{array}{l}\text { Endesa/Union Fenosa, Telecom } \\
\text { Italia, ONO }\end{array}$ \\
\hline France & 2470 & 11 & $\begin{array}{l}\text { Permitted since the } \\
\text { beginning of } 1998\end{array}$ & $\begin{array}{l}\text { Lyonnaise Cable, France Telecom } \\
\text { Cable } \\
\text { NC Numericable }\end{array}$ \\
\hline United Kingdom & $\begin{array}{l}3232 \\
\text { (teleph. only) }\end{array}$ & 11 & Yes (since 1991) & CWC, Telewest, NTL, General Cable \\
\hline Italy & 200 & 1 & & Stream (Telecom Italia) \\
\hline Belgium & 4170 & 95 & Yes (since 1998) & Talent, Brutele, Electrabel \\
\hline Netherlands & 6380 & 96 & $\begin{array}{l}\text { Yes (since July } \\
1997 \text { ) }\end{array}$ & $\begin{array}{l}\text { Casema, NV Telekabel Palet } \\
\text { Kabelcom, NV CasTel }\end{array}$ \\
\hline Denmark & 1400 & 55 & & $\begin{array}{l}\text { Tele Danmark Kabel (Tele } \\
\text { Danmark), Stofa }\end{array}$ \\
\hline Greece & Negligible & & & \\
\hline Portugal & 395 & 12 & & $\begin{array}{l}\text { TV Cabo Portugal (Portugal } \\
\text { Telecom) }\end{array}$ \\
\hline Ireland & 590 & 57 & & Cablelink, Prince Holdings, CMI \\
\hline Austria & 938 & 30 & Yes & Telekabel, Telesystem Tirol \\
\hline Sweden & 2450 & 61 & $\begin{array}{l}\text { Yes (allowed but } \\
\text { not operative yet) }\end{array}$ & $\begin{array}{l}\text { Telia InfoMedia-TV, Kabelvision, } \\
\text { Stjarn-TVNatet, Sweden-On-Line }\end{array}$ \\
\hline Finland & 854 & 37 & Yes & HTV, Sonera \\
\hline
\end{tabular}

${ }^{a}$ Source: Cable and Satellite Yearbook (1999) and New Media Markets and Yearbook of European Telecommunications (1999).

In the meantime, indirect access will remain an important route for many customers who are not in the footprint of competing operators to receive the benefits of competitive telecoms provision.

In other EU members where the PTOs already owned substantial cable networks, such as Germany, Denmark and the Netherlands, the European Commission has put pressure to divest their cable operations. ${ }^{5}$ Table 1 shows the extent of development of cable networks in the EU.

Technological change is also affecting the PTOs' market power over the local loop. Mobile telephony was launched in the mid-1980s as an expensive service tailored to business customers. Since then it has grown exponentially reaching penetration rates in excess of $50 \%$ in Scandinavia.

\footnotetext{
${ }^{5}$ In a number of EU countries, PTOs have divested their cable assets (Ireland, Portugal and Germany) and others are in the process of doing so (i.e. Telia in Sweden and Telenor in Norway).
} 
Table 2

Mobile Networks in the EU

\begin{tabular}{lcllr}
\hline Country & $\begin{array}{l}\text { Mobile lines } \\
(\text { Jan 2000) }\end{array}$ & $\begin{array}{l}\text { Mobile penetration } \\
(\%)\end{array}$ & $\begin{array}{l}\text { No. of mobile } \\
\text { networks }\end{array}$ & Fixed lines (1997) \\
\hline Finland & 3399 & 65.9 & 3 & 2861 \\
Sweden & 5083 & 57.4 & 3 & 6010 \\
Italy & 30,068 & 52.6 & 3 & 25,698 \\
Denmark & 2682 & 51.6 & 4 & 3339 \\
Austria & 3936 & 59.2 & 3 & 3726 \\
Portugal & 4681 & 47.1 & 3 & 4002 \\
Netherlands & 6699 & 42.7 & 5 & 8860 \\
UK & 23,944 & 41.0 & 4 & 31,430 \\
Spain & 15,005 & 37.5 & 3 & 15,854 \\
Ireland & 1345 & 37.4 & 2 & 1500 \\
Greece & 3840 & 36.6 & 3 & 5431 \\
France & 20,619 & 35.4 & 3 & 33,700 \\
Belgium & 3179 & 31.8 & 4 & 4939 \\
Germany & 23,250 & 28.3 & & 45,200 \\
\hline
\end{tabular}

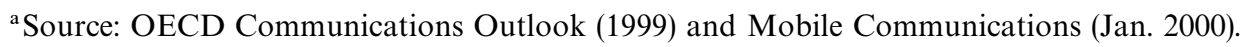

The number of mobile subscribers is rapidly overtaking the number of fixed lines (Table 2) while the number of mobile networks has also increased. ${ }^{6}$ In addition, several EU Member States are awarding licences for narrowband and broadband fixed wireless technologies. These developments are questioning the conceptual framework of almost monopoly provision of access on which the need to regulate access was based. While at the outset of liberalisation the PTO's network could be described as an essential facility, this characterisation is becoming increasingly questionable.

\subsection{Interconnection regulation}

The inherited strength of the incumbent PTOs required the establishment of a regulatory authority to pre-empt potential abuses of market power. Most of the countries require telecommunication operators to negotiate access terms with each other, and only in case of a negotiation failure does the regulator intervene. ${ }^{7}$ At one extreme only New Zealand has so far left the settling process with private negotiations among telecommunication operators, as there is no regulator and in case of disagreement the matter can be referred to the courts under the Competition Act. Other

\footnotetext{
${ }^{6}$ The introduction of the third generation of mobile networks will further increase the number of independent networks as Governments are taking this opportunity to issue additional mobile licences.

${ }^{7}$ For an international survey see Jamison (1999).
} 
countries opted for different degrees of regulatory intervention. In Sweden the regulator can review the incumbent PTO's offer for fairness, but does not have the authority to approve or disapprove once telecommunication operators reached an agreement. In other countries such as the UK, the US and increasingly a number of EU Member States, the regulators are playing a more interventionist role. In the US interconnection agreements are subject to approval by the Federal Communications Commission (FCC) and the Public Utility Commission. In the UK OFTEL directly regulates British Telecom's access charges.

The Interconnection Directive (ICD) extensively shapes the regulatory framework in the EU (see EU Commission, 1997a). ${ }^{8}$ While the ICD does not mandate the National Regulatory Agencies (NRAs) to set interconnection rates directly, ${ }^{9}$ it imposes specific obligations on telecommunication operators and distinguishes telecommunications operators that have significant market power (SMP) from those who do not. There is a presumption that a telecommunications operator has SMP if it has a share of more that $25 \%$ of those telecommunications markets listed in Annex I of the ICD. ${ }^{10}$ These are the fixed public telephone networks, the leased lines service, public mobile telephone networks, public mobile telephone services, and in addition the national market for interconnection. As explained by the EU Commission (1999a) the goal of this ex ante determination of markets was to provide legal certainty to telecommunications operators rather than being based on an economically meaningful definition of markets.

The ICD imposes certain obligations on telecommunications operators authorised by their Member States to provide public telecommunications networks and publicly available telecommunications services, in particular the obligation to negotiate interconnection with each other. Additional obligations are imposed on telecommunication operators, which have been determined as having SMP in a particular market, and, in particular, they are obliged to

I. meet all reasonable requests for access to their networks (Art. 4.2);

II. adhere to the principle of non-discrimination with regard to interconnection offered to others (Art. 6); and

III. more importantly, offer transparent and cost-oriented interconnection charges with a preference for long-run incremental costs methodologies (Art. 7.2). This obligation applies to fixed network operators and only to those mobile networks that have been defined as having SMP in the national market for interconnection.

\footnotetext{
${ }^{8}$ The 1999 Communications Review (EU Commission 1999b) will modify the current framework. The proposed new framework will replace the SMP concept with that of dominance imported from EU competition law.

${ }^{9}$ This emerges from its fifth recital: "whereas organisations authorised to provide public telecommunication networks or publicly available telecommunications services in all or part of the Community should be free to negotiate interconnection agreements on a commercial basis in accordance with Community Law, subject to supervision and, if necessary, intervention by national regulatory authorities ....".

${ }^{10}$ Other criteria used in the SMP determination are "the organisation's ability, its turnover relative to the size of the market, its control of the means of access to end-users, its access to financial resources and experience in providing products and services in the market" (EU Commission, 1997a, Art. 4.3).
} 


\section{Regulatory concerns over call termination}

The development of local loop infrastructure alternative to that of the former PTO was considered crucial for the development of competition and for the withdrawal of regulation of network access. OFTEL (1997a, para 1.5) in setting BT's network charges stated that:

... the time is now right to move away from the current system by which OFTEL determines the charges for BT's standard inter-connection services each year. This system was appropriate as new operators entered the market for the first time following the move from duopoly to full liberalisation in 1991. It has worked well, but the level of regulatory intervention in setting charges which it requires is increasingly inappropriate as competition has become established and continues to develop. OFTEL believes that a new system where BT sets charges subject to flexible controls geared to the level of competition in interconnect services will better serve the industry by maximising the degree to which markets decide charges and reducing as far as possible the intervention of the regulator. The new network charge controls will provide this flexibility within a framework of rules which will protect competitors in markets for interconnect services in which competition is not yet sufficiently strong to allow BT pricing freedom.

However, concerns about gradually relinquishing regulatory control of access have recently emerged. The whole theoretical and regulatory framework at the basis of access regulation is still based on the assumption of monopoly provision of access, in almost all cases by a vertically integrated firm, and is not well equipped to operate in a multi-network environment. Network competition makes the conceptual and consequently practical aspect of access more complex. The regulatory reaction to these difficulties was not as expected - a relinquishing of detailed access regulation with a gradual shift of emphasis on ex post control based on competition law. The idea that economic regulation was only a temporary means to help the transition from monopoly to competition is being gradually abandoned, at least for call termination. ${ }^{11}$ On the contrary, there are signs that the scope of call termination regulation is increasing. While only the incumbents' termination charges have been regulated since liberalisation, there is a growing tendency to directly regulate call termination rates for new networks, such as mobiles, and there is a debate on whether to extend regulation to calls terminating into "non-dominant" fixed networks. This indicates that the widening scope of call termination regulation is not a temporary measure but a response to a belief that network competition will not be sufficient to constrain the network operators' behaviour.

The regulatory concern for call termination relies on two types of arguments. At one extreme call termination is defined as a monopoly, therefore requiring regulation independent of market structure and competitive constraints. The second argument put forward is that regulation is necessary because negotiations to set reciprocal interconnection charges may be used as a vehicle for colluding in the retail market, via high interconnection charges.

\footnotetext{
${ }^{11}$ The degree of regulation on call origination, on the other hand, has been gradually softened in the UK by moving from detailed price caps on individual services to a global price cap where BT has the freedom to rebalance its prices subject to the constraint that its prices do not raise by more than a weighted average cap.
} 
The consequence of adopting this approach is that network competition would not relieve regulators from directly setting terms and conditions for call termination. On the contrary, the emergence of network competition increases manifolds the number of reciprocal interconnection relations that telecommunications network operators have to negotiate among each other. The implications for regulation would be an increasing effort to monitor and potentially regulate call termination charges to an increasing number of networks.

\subsection{The "Bottleneck Theory"}

In recent years OFTEL has repeatedly defined call termination as a bottleneck monopoly independent of the competitive situation. This reflects OFTEL's view that call termination is an inherent natural monopoly that is bound to require continuous regulation. In its recent Draft Competition Guidelines OFTEL (1999a, para 3.5) referred to call termination as the "call termination externality":

this externality relates to termination of calls which originate on different networks. The effect arises because the person originating the call is not the customer of the operator who terminates the call. The terminating operator will be able to raise the price of termination with no direct effect on its own customers. The call termination externality represents a major barrier to effective competition and even in a competitive market may allow excessive pricing.

This concept of call termination as a natural monopoly was reiterated in a recent OFTEL (1999b, paras 2.9 and 2.10) consultative document on competition in mobile call origination:

Telephony markets, both mobiles and fixed, are characterised by a form of market failure which affects the prices charged for terminating calls. This market failure arises because, in the UK, the originating party usually pays for the call but has no choice over which operator terminates the call. This is determined by the called party, who does not pay for the call. This separation of call payment from choice of terminating operator provides the latter with the ability to maintain high access prices for call termination. This failure is inherent in telecoms networks and may not be fully addressed by the market even where there is strong competition to provide call origination. This means that the state of competition in calls from mobiles must be assessed independently of that in calls to mobiles.

The Information Society directorate of the EU Commission (1999b, pp. 28, 29) in its recent consultative document on the 1999 Communications Review also appears to have embraced the theory that competition in call termination is unfeasible by stating that "under the current tariff regime of calling party pays, it is anticipated that the market for local call termination will remain essentially uncompetitive". This view is more an assertion than a result of economic analysis and has drastic consequences. The presence of several competing networks would reduce the need for price-regulating call origination access as consumers and/or service providers would have a choice of networks other than that of the former PTO. However, call termination being a bottleneck monopoly would always need to be regulated. Although so far OFTEL has imposed price regulation on those firms that it determined having "market power" such as BT and the two 
largest mobile networks, the bottleneck argument if brought to its natural conclusions would imply that call termination would require regulation independently of the network's size. ${ }^{12}$

The issue of the competitive constraints faced by terminating operators has recently arisen for fixed-to-mobile calls. Differently from PTOs, mobile termination charges were not regulated but freely negotiated among telecommunications operators. Mobile termination charges have been the object of several investigations by the European Commission, ${ }^{13}$ the UK Monopolies and Merger Commission, now Competition Commission (CC) ${ }^{14}$ and other national competition authorities (see, for example, AGCM, 1999; AGCOM, 1999). The ACCC (1999) is currently consulting on whether call termination to mobile networks and "non-dominant" fixed networks should be regulated in Australia. Here we focus on the CC decision as it is the most detailed analysis of the issue and implicitly questioned the concept of bottleneck monopoly or call termination externality put forward by OFTEL. The CC agreed with OFTEL that the imposition of a price cap was necessary, however, it rejected OFTEL's view that call termination is a bottleneck monopoly. The CC's analysis focused on whether there were sufficient competitive constraints to prevent the mobile network operators (MNOs) from setting their charges unilaterally independent of their competitors and customers. ${ }^{15}$ The $\mathrm{CC}$ agreed that there were competitive pressures but that these were not yet sufficiently strong to protect inbound callers. The CC (1998a, para 2.171) also implicitly concluded that the market power enjoyed by the MNOs was on balance likely to be temporary:

.... as long as it is mobile phone subscribers who chose the network on which they are to be contacted, the emergence of significant competitive pressure on termination charges in the future seems to depends on three main factors: first, the availability of fully competitive alternatives to a fixed to mobile call; secondly, the proportion of subscribers to mobile 'phone networks that are concerned about incoming call cost; and thirdly, the level of importance that those subscribers attach to incoming call costs relative to other features of their mobile "phone package. We do not rule out that at least the second and third may already be having some limited impact, but not in any sense sufficient to provide an effective constraint on termination charges. Nor can we at this stage identify any particular development that would have much impact and we therefore think it unlikely that the situation we have described in paragraphs 2.161 to 2.164 would change

${ }^{12}$ This conclusion is implicitly confirmed by OFTEL, which has imposed detailed regulation, including call termination, upon Kingston Communications, a local network operator owned by the Kingston upon Hull municipality. The recent or impending introduction of local loop unbundling (LLU) in several EU Member States raises the question of whether regulation of call termination could be extended to operators taking advantage of LLU.

${ }^{13}$ In January 1998, the European Commission launched an investigation into interconnection charges between fixed and mobile operators, opening 15 cases with focus on mobile termination rates and fixed operators' retention charges. Subsequently, in November 1998 the European Commission closed some of these cases because of changes in the fixed and mobile operators interconnection charges. The investigation was concluded in May 1999.

${ }^{14}$ The matter was initially investigated by OFTEL in 1996 and referred to the CC in 1998. The joint CC inquiry examined both mobile network operators' termination charge and the so-called BT's retention rates in two separate reports. The issue of mobile termination rate was dealt with in CC (1998a). The CC (1998b) reported separately on BT's retention rate.

${ }^{15}$ This approach is standard in competition law (see EU Commission (1997b) and for an analysis see Veljanovski (1998)). 
significantly in the near future. However, in such an immature market, with a client base growing in size and experience, a service that is still evolving and has considerable scope for innovation in the application and development of existing technologies, the possibility of significant changes in a somewhat longer period of time cannot be discounted. Having reviewed the various factors which could bring about significant changes beyond the next three or four years, we do not believe that we have sufficient basis to expect that fixed-to-mobile calls would remain immune from effective competition. We conclude that there are not adequate competitive constraints, now, nor will there be for the next three or four years.

The CC's conclusions are based on an analysis of the competitive constraints affecting MNOs in setting their termination charges. OFTEL, on the other hand, based its approach on a mechanistic vision of telecommunications where ex post, that is after a consumer has joined a network, both the originating and terminating ends could be thought as bottlenecks, each monopolised by a network and essential to the completion of a call. ${ }^{16}$ This is partly based on economic literature where specific assumptions lead directly into a finding of call termination pricing above costs. Doyle and Smith, for example, present a model of one fixed line operator and two mobile operators where the demand for mobile outgoing calls depends exclusively on the price for mobile-to-fixed calls, while the demand for fixed-to-mobile calls depends only on its price. Not surprisingly they show that the fixed network sets the price of calls to mobile networks above the cost of making such calls (the sum of the fixed network cost and the mobile termination rate). This result stems from the assumption that the fixed operator is a monopolist that in its maximisation exercise takes costs and mobile termination charges as given. Mobile operators maximise interconnection revenues with respect to termination charges and out-going call revenues with respect to the out-going retail price. ${ }^{17}$

By assuming that call termination is an inherent monopoly, OFTEL adopted a shortcut to avoid the complex analysis that the relinquishing of the assumption of monopoly provision of network

${ }^{16} \mathrm{~A}$ full account of the main differences between the CC and OFTEL is given in Crocioni and Veljanovski (1999).

${ }^{17}$ Doyle and Smith (1998) put forward two proposals to reduce the supposed market power enjoyed by mobile operators over call termination. In the UK the party that makes the call pays for the whole service. They propose to introduce a type of receiver pays principle (RPP) in order to change the incentive faced by mobile operators and consumers. They suggest that the fixed operator sets a price for calls to the mobile operators equal to the price charged for calls to other fixed networks (regulated) and the mobile subscribers pay the rest of the charge. The key difference is that the posted price of an incoming call to a mobile network would become a determinant of demand for mobile services. They conclude that "the more responsive calls to mobiles are in response to the demand for mobile services, the closer are termination charges to incremental costs" (p. 15). The prices set for calls to mobile phones affect and are affected by the prices set for calls made from mobile phones to fixed networks. This implies that increased competition in the mobile services would feed through the RPP into the incoming calls. Increasing competition in mobile services should be encouraged in order to increase the competitive pressure on mobile in-bound calls. However, when the assumption that demand for mobile services is independent of the price of making calls to mobiles is refuted, the model collapses as RPP is no longer needed in order to provide a link between demand for mobile services and mobile incoming prices. Although RPP would make this link explicit it is not immune from pitfalls. A general economic principle calls for the cost to be allocated to those who "caused" them. The utility enjoyed (and the cost involved) by calling a mobile phone from a fixed line are higher than those enjoyed by calling another fixed line phone. Making the cost to call a mobile or another fixed line identical for the caller distorts the latter's decision-making. Not all the calls received by a mobile subscriber add to its utility. RPP would prevent mobile subscribers from filtering the calls and would force him/her to pay for the costs of services he/she does not demand. 
access requires. The EU Commission (Competition Directorate) appears more sceptical towards defining call termination as a separate market from call origination. ${ }^{18}$ Although the concept of call termination as a bottleneck monopoly might be specific to OFTEL's thinking, increasingly NRAs are determining mobile operators as having SMP in the national market for interconnection with consequent cost-based interconnection charges. ${ }^{19}$

\subsection{Regulate to prevent collusion?}

So far the access problem was analysed as a one-way issue. A telecommunications network operator needs access to other networks and therefore enters into negotiations with them. Approached in this way, interconnection becomes a vertical issue. However, a crucial feature of network competition is that telecommunications network operators need to agree with each other. There is a major contrast between one-way models of access which describe an asymmetric situation (usually a service provider entrant seeking access to the incumbent's network) and reciprocal (or two-way) models of access based on network competition. Whereas in the former case the main issue is that high access charges can be used to foreclose the downstream market, ${ }^{20}$ in the case of network competition the danger appears to be the use of access charges as a collusive tool in the retail market.

Termination charges are an essential input for any retail tariff and the termination charge paid to the terminating operator represents a cost for the originating operator who also receives payments for terminating the other operator's calls. As an increase in cost necessarily implies an increase in prices by inflating their respective termination charges, telecommunications network operators could increase their respective retail prices and profits provided that the retail demand is inelastic. OFTEL (1997b, para C.14) considered this possibility in its Network Charges from 1997 determination where it expressly referred to this possibility:

There are two important reasons why BT's charges should be cost oriented, even though it has been argued that call termination charges should not be based directly on [Other Local Operators] OLOs' costs. First, there is a need for call termination charges to have a link back to costs, to ensure that 'collusive' outcomes are avoided, in which call termination payments between operators are mutually increased in order to inflate consumer prices to excessive levels .... ${ }^{21}$

${ }^{18}$ In its Access Notice, for example, the EU Commission (1997c, para 47) stated that "The definition of particular product markets - for example, the determination of whether call origination and call termination are part of the same facilities market - is best done in the light of a detailed examination of an individual case." The Italian AGCM (1999) investigated collusive behaviour in call termination by the two Italian mobile operators. Although the market was defined as the provision of mobile termination, the AGCM concluded that there are links between the retail and interconnection markets and that therefore the collusive behaviour was not limited to the interconnection market but also extended to the retail mobile market. This implicitly questions the concept of termination as a bottleneck.

${ }^{19}$ Mobile operators in Sweden, Finland, Austria and Italy (both TIM and Omnitel) are mandated cost-based interconnection (see EU Commission, 1999c).

${ }^{20}$ As PTOs are often vertically integrated, under certain circumstances, they have an incentive to price squeeze competitors by charging a high interconnection charge in order to favour their own retail services.

${ }^{21}$ The other reason for cost orientation considered by OFTEL is that OLOs should face the correct incentives on whether to rely on BT's local network or build their own (the so-called buy or make decision). 
Other competition authorities took into account the potential use of interconnection negotiations to collude in the retail outbound market. ${ }^{22}$ The European Commission (1997c, paras 136, 139 and 142) in its Access Notice also referred to the potential collusive incentive, adding that the exchange of market information that necessarily occurs when two networks interconnect could also be used as a collusive device: ${ }^{23}$

interconnection agreements between network operators may under certain circumstances be an instrument of market sharing between the network operator providing access and the network operator seeking access, instead of the emergence of network competition between them. (...) In the telecommunications sector, it is inherent in interconnection that parties will obtain certain customer and traffic information about their competitors. This information exchange could in certain cases influence the competitive behaviour of the undertakings concerned, and could easily be used by the parties for collusive practices, such as market sharing. (...) Furthermore, access agreements may have an impact on the competitive structure of the market. Local access charges will often account for a considerable portion of the total cost of the services provided to end-users by the party requesting access, thus leaving limited scope for price competition. Because of the need to safeguard this limited degree of competition, the Commission will therefore pay particular attention to scrutinising access agreements in the context of their likely effects on the relevant markets in order to ensure that such agreements do not serve as a hidden and indirect means for fixing or co-ordinating end-prices for end-users, which constitute one of the most serious infringements of Article 85 of the Treaty. This would be of particular concern in oligopolistic markets.

\section{Models of reciprocal access}

A recent strand of economic literature moved away from the typical one-way access model and started to examine the setting of reciprocal (call termination) access charges between two or more network operators that is specific to the telecommunications industry. The main issue relates to the incentive to use reciprocal call termination charges as a collusive device. The outcome depends on the specific assumptions made. A distinction is made between:

I. competition between networks that have their own captive customers (i.e. network operators in different countries) or between networks that compete for the same customers (i.e. overlapping networks);

II. networks that set their reciprocal access charges co-operatively (through negotiation) or nonco-operatively (each network will independently set its access charge);

\footnotetext{
${ }^{22}$ See AGCM (1999, para 251), where the collusive behaviour of the two mobile operators in setting their termination charges was aggravated by the conclusion of the AGCM that interconnection was used as a means to collude in the retail market as well.

${ }^{23}$ While there are other ways in which telecommunications operators could sustain collusion, these are outside the focus of this article.
} 
III. the relative "size" (geographic coverage or customer base) of the networks (symmetric or asymmetric);

IV. the degree of product differentiation of the retail services;

$\mathrm{V}$. the pricing policy adopted (linear pricing or two-part tariffs); and

VI. whether networks are allowed to discriminate between the price of on- and off-net calls.

\subsection{Interconnection without competition for customers}

Armstrong (1996) examined the case of interconnection between two networks that are not competing for final customers. This is the case of two regulated monopolies in their own countries. These networks do not compete directly with each other for customers, but need inputs from each other in order to be able to offer a full service. The typical example is that of international calls where interconnection (call termination) is necessary for the two networks to offer the service. These two "non-competing" networks make profits from two sources: selling their retail services to their captive customers and supplying call termination services to the other operator. In this simple setting the two networks choose their access charges first and the output is determined, assuming the access charge as given. ${ }^{24}$

Armstrong distinguished between non-co-operative and co-operative setting of access charges. In the former case, each operator will set its access charge in order to maximise its profits from selling access and consequently the access charges are set too high. This is an example of the double marginalisation issue that emerges in a vertical setting where the upstream and the downstream firm are both monopolists acting non-co-operatively. ${ }^{25}$ Final prices are higher than the monopoly price. On the other hand, if the two networks act co-operatively in setting their reciprocal access charges and the interests of the two countries coincide precisely, the access charges are identical in the two countries and set at costs. However, if conditions are not symmetric the two networks have

\footnotetext{
${ }^{24}$ Although the provision of international calls between separate countries could be thought as two separate markets, in this case calls from France to Spain and vice versa, there are some caveats. When there are differences in the price of the calls between the two countries consumers will make most of their calls from the country with the lowest price. In addition, firms offering call-back services do not appear to require large price differentials to profitably provide their services. Lam (1997) reports that "evidence in Hong Kong has shown that call-back services have prevailed even when the price differential is small. The price differential between outgoing and incoming calls need not be so large before call-back operators are attracted to the business". See also Frieden (1997). Thus, demand and supply substitution might operate even when telecommunications operators provide services to separate geographic areas.

${ }^{25}$ One can think of interconnection as a vertical issue where the problem of double marginalisation arises from the assumption of monopoly both upstream (provision of access) and downstream (provision of services). Bonanno and Vickers (1988) examined the issue of vertical integration in a context where two manufacturers produce goods that are partial substitutes and compete in price. If they are vertically integrated with their retailer operation and the goods are close substitutes, competition will drive prices down to marginal cost. The implicit assumption is that at the retail level competition is very strong. There is, therefore, an incentive for the two manufacturers to dampen competition at the retail level. This can be achieved through vertical separation. Retailers facing higher marginal cost would increase their price. In this case vertical separation is used by the two producers to dampen the effect of price competition at the retail level. In telecommunications, however, vertical separation is in most cases either structural or imposed by regulation and not a strategic choice.
} 
divergent preferences. A network prefers a lower common access charge if it has greater demand for cross-border traffic and it has lower costs.

The case described above reflects in part the situation for call termination in international calls, even before the telecommunications industry was liberalised. It appears that co-operation between operators achieves a more efficient outcome than independent setting of access charge. This result critically depends on defining the two networks as monopolists in their respective markets. As far as this does not hold and each operator influences each other's behaviour, this case partly becomes similar to the one of networks competing for the same subscribers described below.

\subsection{Interconnection with competition for customers}

The setting of reciprocal interconnection terms between networks that compete for the final customers has been examined by Armstrong $(1996,1998)$ and by Laffont, Rey and Tirole (1997, $1998 \mathrm{a}, \mathrm{b})$. This scenario is becoming more and more relevant as alternative networks to those of the established PTO develop in most EU countries. These new networks consist of both new cable networks, usually capable of providing telephony and other services and wireless networks such as mobiles. Network operators compete for customers and at the same time have to agree reciprocal access terms. Key assumptions consist of balanced calling patterns, ${ }^{26}$ absence of price discrimination between on- and off-net calls, retail linear pricing and horizontally differentiated services.

The general conclusion from these models is that the setting of high access charges can act as an instrument of collusion. Laffont et al. (1997, p. 702) referred to "collusive behaviour concern" according to which "one may then fear that established networks could use their interconnection agreements to facilitate co-operation in the final market as well." The relevant case is that of networks setting co-operatively their reciprocal access charges. ${ }^{27}$ High access charges increase the cost of reducing prices unilaterally. In this respect what differentiates network industries from other industries is what Laffont, Rey and Tirole term access revenue effect. As noted earlier, network operators derive their revenues and profits from providing both retail services and terminating the other network's calls. Suppose now that one network operator unilaterally decides to reduce its retail price. As usual this action has the effect of increasing demand for the services of the network, but it also has an effect which is specific to the telecommunications industry. By increasing the demand for out-bound calls, the decrease in the retail prices increases the access payment to the other network, while the access revenue from the in-bound calls is not affected. A unilateral price reduction would cause a net outflow of calls, therefore creating an access deficit. This access

\footnotetext{
${ }^{26}$ The percentage of calls originating on a network and terminating on the same network is equal to the fraction of consumers subscribing to this network. This means that any given customer is equally likely to call any other user, regardless of the network that user is on. A balanced traffic pattern assumption is at the base of the "peering" agreements between Internet backbone providers where each peer terminates without charge the traffic originating with other peers.

${ }^{27}$ If the networks set non-reciprocal access charges (or non-co-operatively), whereby the networks first set access charges and then retail prices, the double marginalisation problem seen earlier resurfaces again. In the case analysed in this section where the networks are competing, double marginalisation remains for small degree of substitutability.
} 
revenue deficit partly offsets the effect of any retail price reduction. Therefore, the access revenue effect provides network industries with an incentive to increase (or not to reduce) retail prices. ${ }^{28}$

\subsection{Relinquishing some assumptions}

The conclusion that reciprocal access charges are a vehicle for collusion rests on restrictive assumptions. As these are relinquished, most of the collusive concerns fade away. First, a high degree of product substitutability is examined. Second, it is common practice for network operators to adopt two-part tariffs rather than linear pricing. Third, the assumption of non-discrimination between on- and off-net calls is relinquished. Lastly, the models above were based on the assumption that the two networks had identical coverage. When this assumption is relinquished the issue of foreclosure resurfaces.

\subsubsection{The effect of increased substitutability}

According to Armstrong $(1996,1998)$ the use of access charges as a collusive device requires that the two services are neither close substitutes nor that demand is inelastic. If the two services are close substitutes, in other terms if the demand for retail services is elastic, in case of a price reduction the demand effect tends to dominate the access deficit effect and the incentive to unilaterally reduce prices is restored. Similarly, Laffont et al. (1997, 1998a) found that the use of access charges as an instrument of tacit collusion is not the only outcome of the model. Instability of competition is also an outcome. If the access charge is high, the final price is pushed upwards since the access charge is an input in the production of call services. However, when the access charge becomes very high, and if the services are sufficiently close substitutes, each operator has an incentive to undercut its rival and corner the market, therefore creating instability.

\subsubsection{From linear pricing to two-part tariffs}

Laffont et al. (1997, 1998a) examined the effect of modifying the assumption of linear retail pricing to the one of two-part tariffs common in the industry. Two-part tariffs are optimal because they yield pricing at marginal cost. ${ }^{29}$ A key difference with the linear price case is that the equilibrium profit is independent of the access charge. Under the linear pricing case, building market share has the secondary effect of creating an access deficit, the access revenue effect. There is no such countervailing incentive with two-part tariffs, since a network can increase its market share by decreasing its fixed fee to attract new subscribers without generating an access deficit.

As the presence of the access revenue effect was the main factor sustaining tacit collusion by reducing the gains from "cheating" and unilaterally undercutting the competitor's price, two-part

\footnotetext{
${ }^{28}$ Laffont et al. (1998a) further note that if the access charge exceeds the marginal cost of giving access, one network makes money on access if and only if it terminates more calls than it originates, that is if and only if it is more expensive (and inefficient) than its rival.

${ }^{29}$ Marginal cost pricing in the presence of high fixed costs would not allow a regulated monopolist to recover its fixed costs. Two-part tariffs have the advantage that marginal prices are no longer required to cover all costs, and a fixed charge can be used to recover fixed costs and make up any shortfall in profits.
} 
tariffs reduce this competitive concern. Therefore, the industry is more competitive and the operators do not gain any more from access charges. Laffont et al. (1997, p. 706) concluded that with the introduction of two-part tariffs:

the access revenue effect thus disappears and, since this effect is the only one directly related to the access charge, the access charge no longer is a collusive device. (...) Of course, all the traditional reasons which make non-linear prices difficult to design efficiently (incomplete information on consumers' tastes, negative redistributional effects of fixed fees), to the extent that they cannot be overcome by menu of tariffs, are likely to restore partially the tacit collusion effect of high access charges.

\subsubsection{Off-net discrimination}

The assumption that price discrimination between on- and off-net calls is not allowed or not feasible is also crucial to the collusive outcome. For example, in the UK some types of price discrimination are no longer feasible as a consequence of the introduction of number portability. ${ }^{30}$ However, on- and off-net discrimination is feasible and does exist.

Laffont et al. (1998b) showed that the nature of competition in a deregulated telecommunications environment is substantially affected by introducing the possibility of on- and off-net price discrimination. In the absence of price discrimination, a price reduction by one of the networks has the effect of generating an access revenue deficit. If networks were allowed to price discriminate this latter conclusion would not prove true. In fact, a network can increase its market share without necessarily incurring an access deficit by lowering the on-net price while keeping the off-net price constant. This aspect has important consequences for the ability of firms to jack up their reciprocal access charges and use them as a collusive device, as raising each other costs does not promote collusion:

Under price discrimination high access prices may well trigger intense competition for market share and low prices. Intuitively, each network reacts to an increase in the interconnect charge in two ways. First, it raises its off-net price to reflect the increase in its cost of off-net calls. Second, and more interestingly the network faces an enhanced incentive to build markets share in order to reduce the cost of servicing its customers (while this incentive exists under non-discriminatory pricing, the incentive is then mitigated by the fear of building an access deficit) (Laffont et al., 1998b, p. 40).

\subsubsection{Non-symmetric networks}

When the assumption of coverage symmetry between the two networks is abandoned, the issue of foreclosure of the market by the incumbent or larger network re-emerges. Armstrong (1996) relinquished the symmetric network coverage hypothesis to set up a model where there is an

\footnotetext{
${ }^{30}$ Under the current arrangements for number portability in the UK it is not possible for the network where the call originates to detect where the call terminates. This is because if the receiving caller ported his or her number to another network, the call appears to terminate on the network that he or she originally subscribed. Number portability is limited to fixed-to-fixed or mobile-to-mobile networks only.
} 
entrant and a dominant incumbent whose retail price is regulated. The model further assumes that there is a switching cost to move to the entrant (the entrant has to offer a discount in order to capture market share). A common access charge is also assumed. Since the profit of the entrant is a decreasing function in the access charge, the model incorporating a consumer switching cost predicts that the entrant would prefer lower common access charge, everything else equal. Entrant and incumbent, therefore, have different preferences for access charges.

Laffont et al. (1998a) examined the issue of access terms when the entrant has originally no network, while the incumbent has full coverage. If unbundling is allowed, the entrant leases the local transmission facilities from the incumbent. The issue is not reciprocal setting of access price but the efficient level of the access charge to the incumbent's network. When unbundling is not available the authors distinguished between two cases. If interconnection at some access price is mandated by the regulator, the incumbent has a stronger incentive to raise the retail price since it can exploit its captive market (if price discrimination was allowed this incentive would not exist). The entrant, on the other hand, is not handicapped by its smaller coverage. If, on the other hand, interconnection negotiations are unconstrained, the incumbent by insisting on a high access charge might de facto refuse to interconnect with the entrant. The entrant is at a disadvantage unless it duplicates the incumbent's coverage in order to improve its bargaining position.

Market foreclosure could be achieved also by price discriminating between on- and off-net calls. Laffont et al. (1998a) examined this issue in detail. With a balanced calling pattern, and in the absence of price discrimination, an incumbent cannot squeeze an entrant out of the market using high access charges because, at equal prices, incoming and outgoing calls balance. However, if a full coverage (or larger subscriber base) incumbent is allowed to price discriminate, it can force an entrant to exit the market by imposing a high access charge. The latter raises the entrant's cost of off-net calls creating a de facto lack of interconnection. A small network coverage entrant is then at a disadvantage unless it finds it profitable to quickly achieve larger network coverage.

\subsection{A taxonomy of cases}

This overview of the literature on reciprocal interconnection qualifies under which circumstances network operators have an incentive to raise reciprocal interconnection charges in order to collude in the retail market. In most cases this outcome proves not to be a concern. The use of two-part retail tariffs, a standard practice in the industry, undermines the incentives to collude. Similarly, the higher is substitutability between retail services the more unlikely the collusive outcome is. Telecommunications basic services, such as voice telephony, are a relative homogeneous product whose substitutability is high. Furthermore, the explosive growth of mobile networks is increasing call-by-call substitutability between fixed and mobile services. ${ }^{31}$ Discrimination between on- and off-net calls when feasible is also making collusion unlikely.

\footnotetext{
${ }^{31}$ Substitutability between fixed and mobile services takes place at two levels: (a) take-up where the two services are considered as substitutes; and (b) usage, where the two services are complements (an individual subscribes to both) and substitution takes place on a call-by-call basis.
} 
The risk of collusion appears to remain between non-overlapping networks (such as those of former PTOs in each EU countries) that do not compete for the same subscribers. The expansion of former PTOs into other EU Member States and the presence of arbitrage opportunities through call back, however, partially undermine the idea that networks that are not based in the same area do not compete with each other. More importantly, a potential risk of market foreclosure remains when the relative size of the networks is asymmetric. When a large (either in terms of coverage or customer base) network overlaps and, therefore, directly competes for final customers with a smaller network, it may use high access charges to its network to put the smaller network at a disadvantage.

\section{Concluding remarks}

This article explored the increasing concern of regulators over call termination. Two types of concerns are put forward to support increasing regulation of call termination. The extreme argument is that call termination is a bottleneck monopoly and that, therefore, network operators charge a monopoly or excessive price to terminate calls to their networks. The characterisation of call termination as a bottleneck monopoly was relied upon by OFTEL for examining fixed-tomobile calls and although rejected by the CC still features in recent OFTEL's documents. The CC confirmed that call termination cannot be described as a bottleneck monopoly, but that the market power of the terminating network operators varies depending on the circumstances of the case. Competitive constraints over call termination might be weak in some cases, but call termination cannot be always described as a bottleneck monopoly. Therefore, a more flexible approach is necessary in order to assess the competitive conditions that exist in each case.

The risks of using reciprocal access negotiations in order to collude in the retail market have been emphasised in OFTEL, the ACCC and the European Commission's consultative documents and legislation. These risks are often based on a superficial interpretation of the economic literature. This brief literature review indicates that a collusive use of reciprocal interconnection agreements cannot be ruled out. However, the conditions that make this likely are rather restrictive. Therefore, it cannot be assumed that the risks from an improper use of interconnection negotiations are sufficiently high to justify pre-emptive regulation of call termination.

The EU 1999 Communications Review is a process of revision of the existing EU regulatory framework. It is important that the issues raised by call termination be carefully examined. While call termination is likely to continue to require regulation, especially in the case of service providers seeking access to the PTOs' networks, extending regulation to call termination services exchanged between network operators does not appear justifiable. Terming call termination a bottleneck monopoly simplifies the work of regulators at the risk of introducing unnecessary regulation in a period in which the effects of the telecommunications liberalisation start to unfold.

\section{References}

Armstrong, M. (1996). Network interconnection. Discussion Paper in Economics and Econometrics, No. 9625, University of Southampton.

Armstrong, M. (1998). Network interconnection in telecommunications. Economic Journal, 108, 545-564. 
Australian Consumer and Competition Commission (ACCC). (1999). Principles for determining access prices for domestic GSM terminating access and domestic GSM originating access services. Discussion Paper, December.

Autoritá Garante della Concorrenza e del Mercato (AGCM). (1999). TIM-Omnitel Tariffe Fisso Mobile. Provvedimento n. 7553 (I372), 28 September.

Autoritá per le Garanzie nelle Comunicazioni (AGCOM). (1999). Interconnessione di terminazione verso le reti radiomobili e prezzi delle comunicazioni fisso-mobile originate dalla rete di Telecom Italia. Delibera n. 338/99, 6 December.

Bonanno, G., \& Vickers, J. (1988). Vertical separation. The Journal of Industrial Economics, 36, 257-265.

Crocioni, P., \& Veljanovski, C. (1999). Pricing calls to mobiles. Telecommunications Policy, 23, 539-555.

Doyle, C., \& Smith, J. C. (1998). Market structure in mobile telecoms: Qualified indirect access and the receiver pay principle. Regulation Initiative Discussion Paper, No. 21.

EU Commission. (1997a). Directive 97/33/EC on interconnection in telecommunications with regard to ensuring universal service and interoperability through application of the principles of Open Network Provision, 30 June 1997, OJ L 199/32 (pp. 32-52).

EU Commission. (1997b). Notice on the definition of the relevant markets for the purposes of Community competition law, 9 December 1997, OJ C 372/5 (pp. 5-13).

EU Commission. (1997c). Notice on the application of the competition rules to access agreements in the telecommunications sector, 22 August 1998, OJ C 265/2 (pp. 2-28).

EU Commission. (1999a). Explanatory note of 1 March 1999 concerning determination of organisation with significant market power (SMP) for implementation of the ONP directives.

EU Commission. (1999b). Towards a new framework for Electronic Communications infrastructure and associated services, October (pp. 28, 29).

EU Commission. (1999c). Notification of organisation with significant market power, 15 September.

Frieden, R. M. (1997). The impact of call-back and arbitrage on the accounting rate regime. Telecommunication Policy, 21, 819-827.

Jamison, M. A. (1999). International survey of interconnection policies. Mimeo, January, in http://www.bear. cba.ufl.edu/cebters/purc/primary/PUBLICAT/interconn.html.

Laffont, J. J., Rey, P., \& Tirole, J. (1997). Competition between telecommunications operators. European Economic Review, 41, 701-711.

Laffont, J. J., Rey, P., \& Tirole, J. (1998a). Network competition: I. Overview and non discriminatory pricing. RAND Journal of Economics, 29, 1-37.

Laffont, J. J., Rey, P., \& Tirole, J, . (1998b). Network competition: II. Price discrimination. RAND Journal of Economics, 29 , $38-56$.

Monopolies and Mergers Commission (now Competition Commission - CC). (1998a). Reports on references under section 13 of the Telecommunications Act 1984 on the charges made by Cellnet and Vodafone for terminating calls from fixed-line networks, December.

Monopolies and Mergers Commission (now Competition Commission - CC). (1998b). A report on a reference under section 13 of the Telecommunications Act 1984 on the charges made by British Telecommunications plc for calls from its subscribers to 'phones connected to the networks of Cellnet and Vodafone, December.

Mueller, M. (1998). On the frontier of deregulation: New Zealand telecommunications and the problem of interconnecting competing networks. In: D. Gabel, \& D. F. Weiman (Eds.), Opening networks to competition: The regulation and pricing of access. Dordrecht: Kluwer Academic.

OFTEL. (1996). OFTEL's policy on indirect access, equal access and direct connection to the access network: Statement from the Director General of Telecommunications, July.

OFTEL. (1997a). Network charges from 1997, May.

OFTEL. (1997b). Network charges from 1997, July.

OFTEL. (1998). Effective competition review statement, February.

OFTEL. (1999a). Draft guidelines on the application of the Competition Act in the telecommunications sector, January.

OFTEL. (1999b). Competition in the mobile market, February.

Pun-Lee Lam. (1997). Erosion of monopoly power by call-back. Telecommunication Policy, 21, 693.

Veljanovski, C. (1998) The economics of the relevant market in EC competition law, 185. International Review of Competition Law, 185, 4-10. 